\title{
Vaccination in adults with autoimmune rheumatic diseases
}

\author{
Timothy S.H. Kwok MD, Michael Libman MD, Shirley L. Lake MD MSc
}

Cite as: CMAJ 2019 September 9;191:E1005. doi: 10.1503/cmaj.190345

\section{1} Vaccination status should be assessed at diagnosis and periodic examinations in patients with rheumatic diseases

Patients with rheumatic disease have 1.4-2.0 times the risk of infection as the general population. ${ }^{1}$ Although vaccination is recommended for all patients with rheumatic disease, uptake is suboptimal. ${ }^{2}$

2 Inactivated vaccines are safe and generally effective in patients receiving disease-modifying antirheumatic drugs Inactivated vaccines, including influenza, pneumococcal, tetanus, human papillomavirus, Haemophilus influenzae type B, meningococcal and hepatitis A and B, are safe in patients receiving conventional synthetic disease-modifying antirheumatic drugs (DMARDs) and biologic DMARDs. ${ }^{2}$ Data on vaccine response in patients receiving DMARDs are limited. Meta-analysis suggests diminished response to pneumococcal vaccination with methotrexate but not tumour necrosis factor inhibitors. ${ }^{3}$

\section{3}

Ideally, vaccination administration should be completed before treatment and during stable disease, but do not unduly delay or hold DMARD treatment

Although no studies have compared vaccination efficacy and harms in stable and unstable rheumatic disease, vaccination should start when symptom burden and inflammatory markers are low, ideally 2 weeks or more before DMARD initiation. ${ }^{2}$ Although studies of activity showed no more vaccine-associated disease flares in patients with moderate to severe disease than in an unvaccinated control group, this remains a theoretical risk. ${ }^{4}$

4 Live vaccines should be avoided in patients receiving biologic DMARDs Live vaccines including herpes zoster (Zostavax), measles-mumps-rubella, poliomyelitis and varicella should be given 4 weeks before starting biologic DMARDs and avoided in patients already receiving biologic DMARDs. ${ }^{2}$ If benefits outweigh risks, biologic DMARDs can be suspended and the live vaccine administered based on the biologic DMARD's pharmacokinetic properties. ${ }^{2}$ For example, for biologic DMARDs such as rituxamab (a B cell therapy given every $6 \mathrm{mo}$ ), inactivated vaccines should be given 5 months or more after the last dose and at least 4 weeks before the subsequent dose. ${ }^{2}$ Clinicians should consider vaccinations indicated for future travel before immunosuppression.

5 All vaccinations can be given on the same day

If no contraindications exist, patients can be vaccinated at a single visit according to local immunization schedules and risk factors (Appendix 1, available at www.cmaj.ca/lookup/suppl/doi:10.1503/cmaj.190345/-/DC1). Both serious and mild adverse events such as nausea, fever and myalgia occur at rates similar to those in people without autoimmune disease. ${ }^{5}$

\section{References}

1. Listing J, Gerhold K, Zink A. The risk of infections associated with rheumatoid arthritis, with its comorbidity and treatment. Rheumatology (Oxford) 2013;52:53-61.

2. Papp KA, Haraoui B, Kumar D, et al. Vaccination guidelines for patients with immune-mediated disorders taking immunosuppressive therapies: executive summary. J Rheumatol 2019;46:751-4.

3. Subesinghe $\mathrm{S}$, Bechman K, Rutherford Al, et al. A systematic review and metaanalysis of antirheumatic drugs and vaccine immunogenicity in rheumatoid arthritis. J Rheumatol 2018;45:733-44.

4. van Assen S, Agmon-Levin N, Elkayam O, et al. EULAR recommendations for vaccination in adult patients with autoimmune inflammatory rheumatic diseases. Ann Rheum Dis 2011;70:414-22.

5. Glück T, Müller-Ladner U. Vaccination in patients with chronic rheumatic or autoimmune diseases. Clin Infect Dis 2008;46:1459-65.

\section{Competing interests: None declared.}

This article has been peer reviewed.

Affiliations: Department of Medicine (Kwok, Lake), University of Toronto, Toronto, Ont.; J.D. MacLean Centre for Tropical Diseases (Libman) and Division of Infectious Diseases (Libman), Department of Medicine, McGill University, Montréal, Que.; Division of Rheumatology (Lake), Sunnybrook Health Sciences Centre, Toronto, Ont.

Correspondence to: Shirley Lake, Shirley.lake@sunnybrook.ca

CMAJ invites submissions to "Five things to know about ..." Submit manuscripts online at http://mc.manuscriptcentral.com/cmaj 